\title{
RENCANA REVITALISASI KAWASAN PERBELANJAAN PASAR BARU DALAM RANGKA MENINGKATKAN DAYA TARIK SEBAGAI PUSAT PERBELANJAAN BERSEJARAH
}

\author{
Evan Vincent Karta ${ }^{1)}$, Liong Ju Tjung ${ }^{2)}$, Priyendiswara A. B. ${ }^{3)}$ \\ 1)Program Studi S1 PWK, Fakultas Teknik, Universitas Tarumanagara, evanvincentkarta@gmail.com \\ 2) Program Studi S1 PWK, Fakultas Teknik, Universitas Tarumanagara, jt.liong@pps.untar.ac.id \\ 3) Program Studi S1 PWK, Fakultas Teknik, Universitas Tarumanagara, priyendiswaraa@ft.untar.ac.id
}

\begin{abstract}
Abstrak
Tujuan dari penelitian ini adalah untuk meningkatkan daya tarik Pasar Baru agar dapat tetap eksis dan beradaptasi dengan perkembangan zaman, serta trend masa kini, yang diharapkan dapat meningkatkan nilai sosial ekonomi kawasan tersebut. Penelitian yang dilakukan adalah dengan menganalisis kebijakan-kebijakan yang pernah dan sedang diterapkan pada Pasar Baru, menganalisis potensi dan masalah dari lokasi dan tapak Pasar Baru, menganalisis key success factor dari objek studi bandingan, dan menganalisis persepsi serta preferensi masyarakat yang diambil melalui kuesioner. Untuk keseluruhan analisis tersebut dijelaskan secara deskriptif. Dan untuk analisis persepsi masyarakat, kuesioner disebarkan dengan metode purposive sampling karena jumlah populasi tidak diketahui secara pasti. Hasil dari analisis tersebut menunjukkan potensi serta permasalahan yang dimiliki Pasar Baru seperti sarana/prasarana dan infrastruktur yang tidak terawat sehingga mengurangi kenyamanan pengunjung. Isu ini tentu akan menjadi salah satu faktor yang dapat mengancam eksistensi kegiatan ekonomi di Pasar Baru, yang tentunya tidak kita inginkan. Maka dari itu sudah selayaknya potensi Pasar Baru terus dikembangkan lebih lanjut, dan memperbaiki permasalahan yang terdapat pada pusat perbelanjaan Pasar Baru. Mengingat Pasar Baru sebagai salah satu pusat perbelanjaan tertua di Jakarta, yang merupakan peninggalan Bangsa Belanda dari tahun 1820 dan masih eksis hingga saat ini. Rencana revitalisasi ini yaitu mengedepankan perbaikan dari insfrastruktur jaringan jalan serta kegiatan yang terdapat di kawasan perbelanjaan Pasar Baru dengan hasil akhir yang dikeluarkan adalah masterplan dari koridor perbelanjaan Pasar Baru dalam bentuk 3D.
\end{abstract}

Kata kunci: Infrastruktur; Pusat Perbelanjaan; Revitalisasi

\begin{abstract}
The purpose of this study is to increase the attractiveness of Pasar Baru so it can continue to exist and adapt to the times, as well as current trends, which are expected to increase the socioeconomic value of the region. Research carried out is by analyzing policies that have been and are being applied to Pasar Baru, analyzing the potential and problems of the Pasar Baru by it location and site, analyzing key success factors from benchmark, and analyzing perceptions and preferences of the people taken through questionnaires. The overall analysis is explained descriptively. And for the analysis of community perceptions, the questionnaire was distributed using a purposive sampling method because the population was not known for sure. The results of the analysis show the potential and problems that Pasar Baru has such as untreated facilities and infrastructure so it can't give visitors a comfort in shopping. This issue will certainly be one of the factors that can threaten the existence of economic activities in Pasar Baru, which of course we don't want. Therefore, the potential of Pasar Baru should be developed further, and fix the problems in the Pasar Baru shopping center. Given Pasar Baru as one of the oldest shopping center, which is a relic of the Dutch from 1820 and still exists today. This revitalization plan which is prioritizing the improvement of the road network infrastructure and activities in the Pasar Baru shopping area with the final output is a 3D model masterplan of the Pasar Baru shopping corridor.
\end{abstract}

Keywords: Infrastructure; Revitalization; Shopping Center 


\section{PENDAHULUAN}

Di Jakarta, terdapat banyak lokasi bersejarah yang hingga saat ini masih menjadi pusat kegiatan. Pusat-pusat kegiatan ini umumnya berupa pusat perbelanjaan, kawasan bersejarah, dan lainnya. Seperti Kawasan Kota Tua, Monas, Menteng, Cikini, Glodok, Pasar Baru dan lainlainnya. Semua lokasi tersebut masih memiliki daya tariknya masing-masing dan masih menjadi pusat kegiatan parisiwata di Jakarta. Tidak sedikit yang menjadi lokasi tujuan wisatawan manca negara. Sehingga sangat penting untuk terus mendukung kelangsungan pusat-pusat kegiatan tersebut agar terus dapat berkembang dan semakin menarik bagi banyak kalangan.

Tetapi sayangnya, masih banyak terdapat kekurangan pada lokasi-lokasi tersebut seperti fasilitas yang tidak terawat, rusak, hingga tidak tersedianya infrastruktur yang memadai seperti akses untuk kaum difabel. Hal ini merupakan sebuah batasan bagi orang-orang tertentu untuk mengakses lokasi tersebut sehingga jumlah pengunjung tidak maksimal. Jumlah pengunjung tidak maksimal akan menyebabkan menurunnya potensi perekonomian dari lokasi tersebut. Maka dari itu, mengingat pentingnya faktor-faktor di atas, sangat diperlukan upaya pemugaran, penataan serta pemeliharaan kawasan-kawasan tersebut yang sebenarnya masih memiliki potensi lebih besar jika dikelola dengan baik.

Dalam kasus penulisan ini, terdapat satu lokasi yang diangkat menjadi lokasi objek studi untuk ditata ulang karena secara eksistingnya masih banyak memiliki kekurangan seperti fasilitas yang kurang baik dan infrastruktur di lokasi yang tidak terawat. Lokasi tersebut adalah kawasan pusat perbelanjaan Pasar Baru, terletak di Kelurahan Pasar Baru, Kecamatan Sawah Besar, Jakarta Pusat. Pasar Baru merupakan salah satu pusat perbelanjaan tertua di Jakarta karena sudah beroperasi sejak abad 19, yaitu pada tahun 1820. Terletak dekat dengan pusat pemerintahan pada zaman penjajahan Belanda maupun pusat pemerintahan pada saat ini, menjadikan Pasar Baru pusat perbelanjaan yang strategis secara lokasi. Pasar Baru pun sudah ditetapkan oleh Gubernur DKI Jakarta sebagai kawasan perbelanjaan bertaraf internasional melalui Surat Keputusan Gubernur DKI Jakarta No. 3048 Tahun 2000.

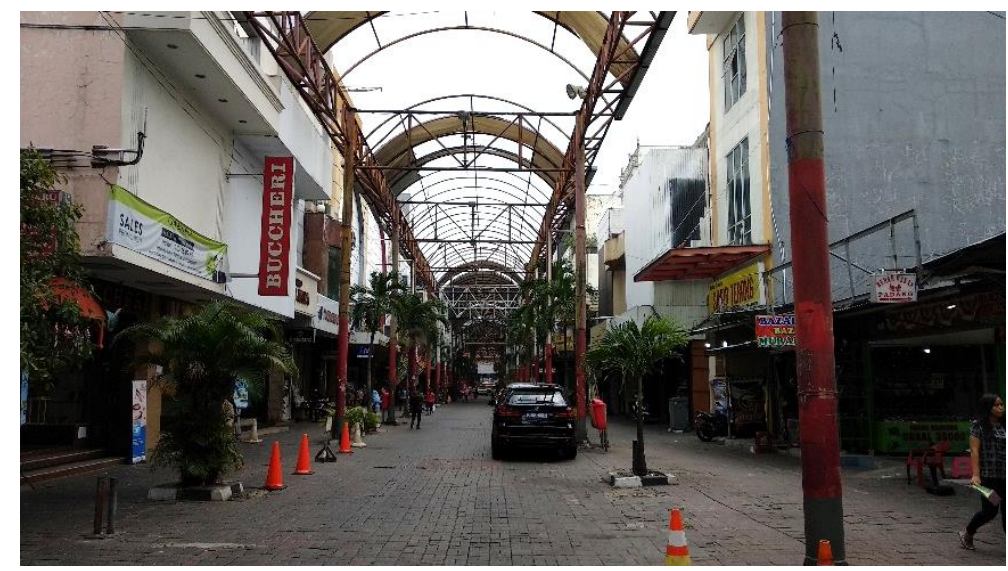

Gambar 1. Kondisi Eksisting salah satu Fasilitas di Pasar Baru, Kanopi Sumber: Penulis, 2018

Tetapi seiring munculnya pasar-pasar modern yang baru seperti mall-mall, pamor Pasar Baru dapat terancam menurun. Para konsumen juga berpotensi meninggalkan Pasar Baru dalam memenuhi kebutuhannya. Sangat disayangkan apabila kawasan dengan potensi yang besar ini sampai ditinggalkan konsumen sehingga aktivitas perekonomian menurun bahkan terancam hilang. Maka dari itu diperlukan upaya penataan dan pemugaran Pasar Baru yang bertujuan untuk meningkatkan daya tariknya agar tetap dapat bersaing dengan pasar-pasar modern serta memiliki nilai jual tersendiri yang tentunya tidak dimiliki oleh pasar-pasar lainnya dan tetap menjadi salah satu destinasi wisata di Jakarta serta meningkatkan nilai sosial ekonomi kawasan tersebut. Berikut objek studi koridor jalan di Pasar Baru dalam tabel. 
Tabel 1. Objek Studi Penelitian

\begin{tabular}{clc}
\hline No. & Nama Jalan & Panjang Jalan (m) \\
\hline 1 & J. Pasar Baru & 533 \\
\hline 2 & Jl. Antara & 405 \\
\hline 3 & J. Pintu Air Raya & 618 \\
\hline 4 & J. Gereja Ayam & 202 \\
\hline 5 & J. Kelinci Raya & 140 \\
\hline & Total Panjang Jalan & $\mathbf{1 8 9 8}$
\end{tabular}

Sumber: Penulis, 2018

\section{KAJIAN LITERATUR}

Berikut adalah kajian literatur dari penelitian :

Menurut Danisworo, Revitalisasi adalah upaya untuk memvitalkan kembali suatu kawasan atau bagian kota yang dulunya pernah vital/hidup, akan tetapi kemudian mengalami kemunduran (Degradasi). Skala revitalisasi ada 2 tingkatan yaitu makro dan mikro. Proses Revitalisasi sebuah kawasan mencakup perbaikan aspek fisik, aspek ekonomi dan aspek sosial. Pendekatan Revitalisasi harus mampu mengenali dan memanfaatkan potensi lingkungan (sejarah, makna, keunikan lokasi dan citra tempat). Menurut Departemen Kimpraswil (2002) Revitalisasi adalah rangkaian upaya menghidupkan kembali kawasan yang cenderung mati, meningkatkan nilai- nilai vitalitas yang strategis dan signifikan dari kawasan yang masih mempunyai potensi dan atau mengendalikan kawasan yang cenderung kacau atau semrawut. Dari pengertian di atas dapat disimpulkan bahwa Revitalisasi adalah upaya untuk menghidupkan kembali fungsi utama, atau dengan kata lain mengembalikan pada vitalitas fungsi utamanya yang telah pudar sebelumnya. Maka dari itu, revitalisasi kawasan bersejarah memiliki tujuan untuk menguatkan kembali nilai-nilai sejarah yang terdapat di kawasan tersebut agar masyarakat lebih mengetahui tentang sejarahnya sekaligus meningkatkan daya tarik melalui nilai-nilai sejarah yang ada.

Wisata kota adalah suatu kegiatan untuk menarik wisatawan domestik maupun mancanegara dengan menyediakan akomodasi dan program kunjungan ketempat yang menjadi daya tarik kota tersebut (Inskeep, 1991). Menurut Law (1996: 1), kota merupakan jenis destinasi pariwisata yang paling penting di dunia sejak tahun 1980-an. Sebagai fenomena kepariwisataan dunia, kota dipandang sebagai suatu proses kompleks yang terkait dengan budaya, gaya hidup, dan sekumpulan permintaan yang berbeda terhadap liburan dan perjalanan (Page, 1995: 1). Pada umumnya, Wisata Kota menawarkan hiburan dalam kota dengan mengunjunginya dan melakukan berbagai kegiatan seperti kunjungan keluarga, menemui teman, menyaksikan pertunjukan-pertunjukan seperti konser musik, opera, pameran atau berbelanja. Sejalan dengan perjalanan waktu, wisata kota juga diramaikan dengan kegiatan konferensi, pertemuan pertemuan berkaitan dengan kegiatan usaha seperti menemui partner usaha, promosi produk maupun promosi perusahaan, partisipasi pameran dan pekan raya, dsb. Wisata Kota pun tidak lepas dari daya tarik lainnya jika perencanaannya dilakukan dengan penuh perhitungan dan pandangan dinamis, seperti misalnya acara-acara festival, karnaval, olah raga yang diselenggarakan secara teratur setiap tahun untuk menarik perhatian dan ketertarikkan pengunjung secara luas, baik wisatawan lokal maupun asing.

Secara umum, pengertian infrastruktur adalah semua jenis fasilitas yang dibutuhkan oleh masyarakat umum untuk mendukung berbagai kegiatan masyarakat dalam kehidupan seharihari. Dengan kata lain, infrastruktur adalah semua fasilitas, baik fisik maupun non fisik yang dibangun oleh pemerintah maupun perorangan untuk memenuhi kebutuhan dasar masyarakat dalam lingkup sosial dan ekonomi. Menurut N. Gregory Mankiw (2003), dalam ilmu ekonomi, arti infrastruktur adalah wujud modal publik (public capital) yang terdiri dari jalan umum, jembatan, sistem saluran pembuangan, dan lainnya, sebagai investasi yang dilakukan oleh pemerintah. Menurut Neil S. Grigg (1998), pengertian infrastruktur adalah sistem fisik yang 
menyediakan sarana drainase, pengairan, transportasi, bangunan gedung dan fasilitas publik lainnya yang dibutuhkan untuk dapat memenuhi berbagai macam kebutuhan dasar manusia baik itu kebutuhan sosial maupun kebutuhan ekonomi. Menurut Robert J. Kodoatie (2005), pengertian infrastruktur adalah suatu sistem yang menunjang sistem sosial dan ekonomi yang secara sekaligus menjadi penghubung sistem lingkungan, dimana sistem ini bisa digunakan sebagai dasar dalam mengambil kebijakan. Infrastruktur umumnya merujuk pada pembangunan fisik untuk fasilitas umum seperti; jalan raya, bandar udara, pelabuhan, listrik, telekomunikasi, air bersih, pengolahan limbah, rumah sakit, sekolah, dan lain sebagainya. Selain itu, infrastruktur juga merujuk pada hal teknis yang mendukung kegiatan ekonomi masyarakat, seperti; moda transportasi, distribusi barang dan jasa, dan lain-lain.

\section{METODE}

Dalam pengambilan data untuk penelitian ini, penulis mengambil data berjenis primer dan sekunder. Untuk primer yaitu dengan survey lokasi kondisi fisik eksisting Pasar Baru, wawancara kepada Ketua Asosiasi Retail Pasar Baru, Pelaku Usaha dan Pengunjung dan wawancara kepada pengunjung Pasar Baru dengan kuesioner. Lalu untuk data sekunder diperoleh dari artikel, buku dan website instansi pemerintah di internet seperti kebijakan yang terkait dengan Kawasan Perbelanjaan Pasar Baru, dokumentasi dan data sejarah Pasar Baru dan studi kasus lain/benchmark. Teknik pengumpulan data yang dilakukan penulis dengan survey lapangan dan wawancara untuk data primer dan untuk data sekunder diperoleh dari berbagai sumber yang relevan seperti studi literatur, skripsi/tesis, internet, dll. Berikut kerangka pikir dan kerangka analisis dari penelitian berikut.

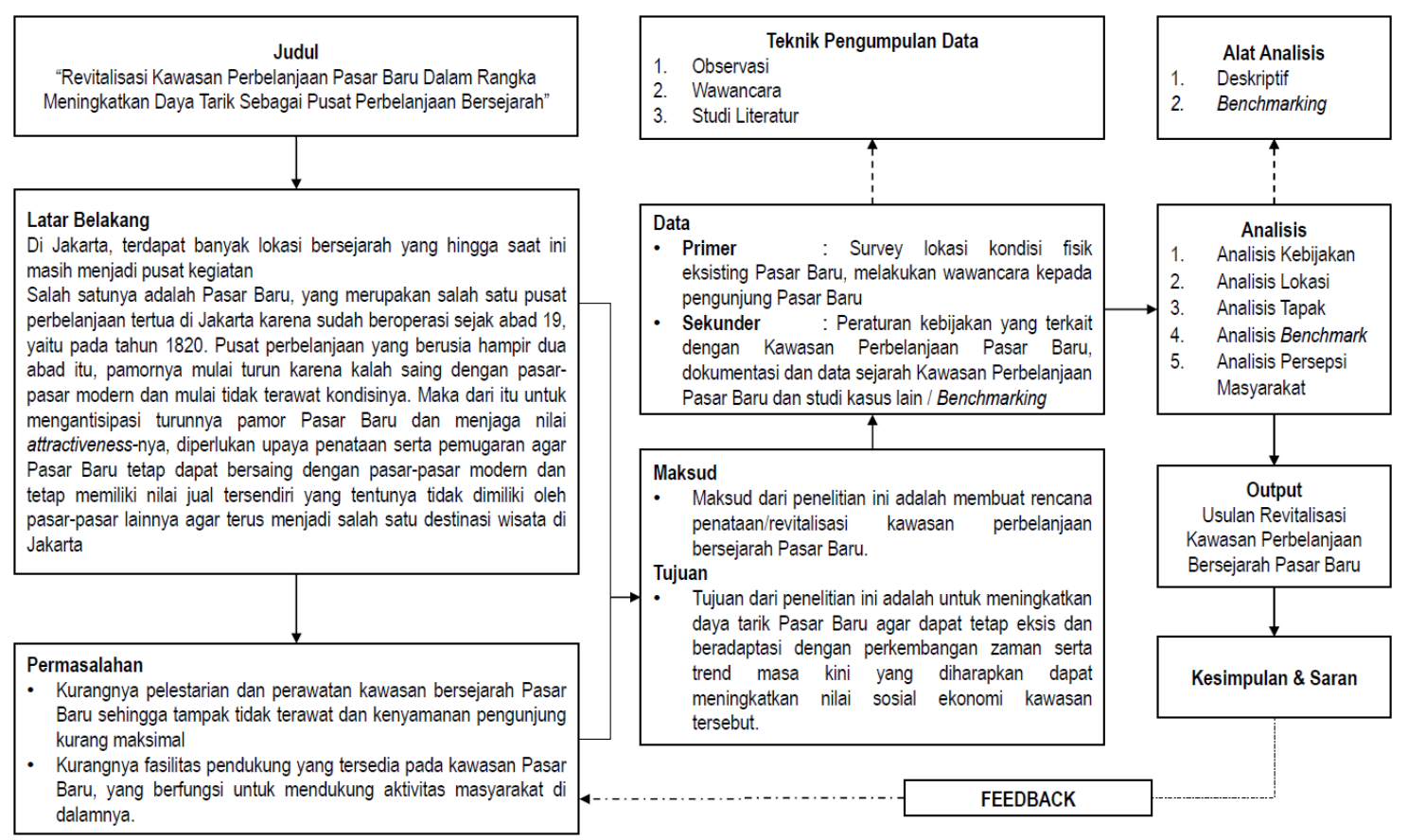

Gambar 2. Skema Kerangka Pikir Penelitian Sumber: Penulis, 2018 


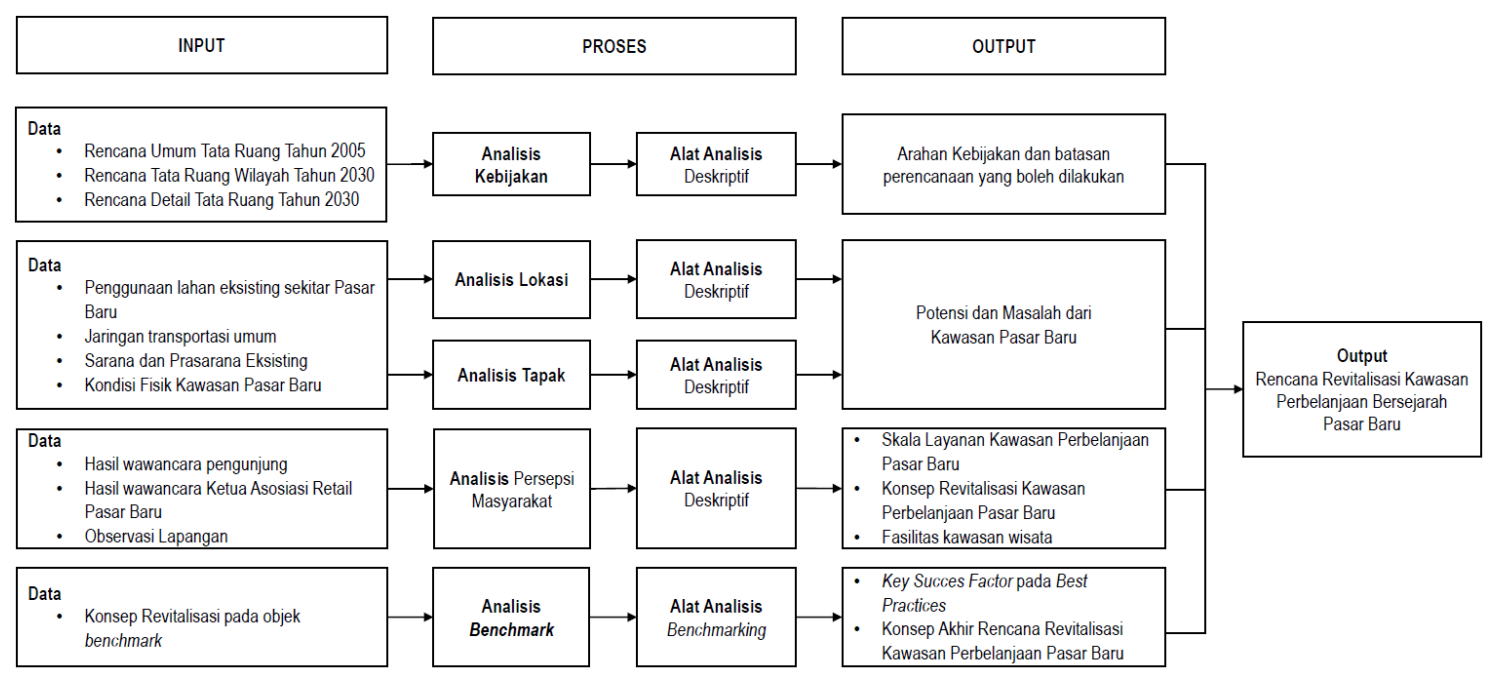

Gambar 3. Skema Kerangka Analisis Penelitian

Sumber: Penulis, 2018

\section{DISKUSI DAN HASIL}

Bedasarkan hasil analisis kebijakan yang membahas tentang RUTR DKI 2005, RDTR DKI 2030 dan RTRW DKI 2030, diketahui bahwa Pasar Baru sudah menjadi kawasan yang penting bagi Ibu Kota Jakarta karena posisinya yang selalu ditempatkan sebagai kawasan komersial dan saat ini direncanakan menjadi pusat kegiatan tersier menurut Peta Struktur Ruang, RTRW DKI 2030. Dari lokasi dan tapaknya, Pasar Baru memiliki potensi dari segi aksesibilitas, dan juga memiliki masalah dalam arus lalu lintasnya yang sering terjadi kemacetan. Dari objek studi bandingan yaitu Boat Quay dan Clarke Quay Singapura, didapatkan beberapa faktor yang dapat menjadi key success factor dari kelangsungannya, seperti pusat kuliner tepi sungai dan kondisi koridor yang terawat dengan desain menarik dari tampak-tampak bangunan dan pencahayaan daripada gedung dan jalanan. Jika melihat segi fisik Pasar Baru, menurut masyarakat terdapat banyak fasilitas yang memiliki tingkat kepentingan tinggi tetapi memiliki tingkat peforma yang rendah, seperti kanopi, kondisi jaringan jalan, fasilitas toilet umumnya, dan lainnya. Persepsi masyarakat didapatkan dari kuesioner yang disebar kepada para pengunjung Pasar Baru dengan jumlah 151 responden.

Maka dari itu, terdapat beberapa hal yang cukup penting untuk segera dibenahi, dan terdapat beberapa usulan perencanaan yang sesuai dengan preferensi masyarakat untuk mengoptimalkan kegiatan kawasan wisata kota Pasar Baru. Mengingat cikal bakal Pasar Baru sebagai salah satu pusat kegiatan pedagang dari Tiongkok, maka konsep penataan yang akan diterapkan adalah China Town, maka dari itu beberapa komponen penataan akan mengarah ke kebudayaan Tiongkok yang dipadukan dengan arsitektur modern. Untuk pembiayaan dari proyek penataan Pasar Baru, tentunya akan berasal dari APBD. Tetapi tidak menutup kemungkinan apabila terdapat investor-investor yang bersedia menjalin kerjasama dengan pemerintah dalam upaya revitalisasi kawasan perbelanjaan Pasar Baru, sehingga penggunaan dana APBD dapat dialihkan kepada hal-hal lain yang tidak kalah penting. Berikut adalah tabel daftar rencana penataan dari setiap objek studi di Kawasan Pasar Baru yang akan ditambahakan dan ditata kembali. 
Tabel 2. Rencana Pekerjaan pada Objek Studi

\begin{tabular}{|c|c|c|}
\hline No. & Koridor & Rencana Penataan/Penambahan Fasilitas \\
\hline \multirow{9}{*}{1} & \multirow{9}{*}{ Jl. Pasar Baru } & Penataan jaringan jalan \\
\hline & & Penanaman kabel listrik bawah tanah \\
\hline & & Pedestrian ramah difabel \\
\hline & & Penyeragaman tema tampak bangunan \\
\hline & & Penggantian jenis lantai \\
\hline & & Penggantian jenis kanopi \\
\hline & & Penyediaan pusat informasi \\
\hline & & Penyediaan public toilet \\
\hline & & Pemberian lighting pada bangunan dan koridor jalan \\
\hline \multirow{6}{*}{2} & \multirow{6}{*}{ Jl. Antara } & Penataan jaringan jalan \\
\hline & & Penanaman kabel listrik bawah tanah \\
\hline & & Pelebaran dan optimalisasi pedestrian yang ramah difabel \\
\hline & & Pembangunan Sheetpile Sungai Ciliwung \\
\hline & & Pembangunan pusat kuliner \\
\hline & & Pemberian lighting pada bangunan dan koridor jalan \\
\hline \multirow{2}{*}{3} & \multirow{2}{*}{ Jl. Pintu Air } & Pembangunan Gapura \\
\hline & & Pelebaran Pedestrian \\
\hline \multirow{2}{*}{4} & \multirow{2}{*}{ Jl. Kelinci Raya } & Pembuatan Pedestrian Ramah Difabel \\
\hline & & Penanaman Kabel Listrik di Bawah Tanah \\
\hline \multirow{3}{*}{5} & \multirow{3}{*}{ Jl. Gereja Ayam } & Pemugaran Gapura \\
\hline & & Pelebaran dan optimalisasi pedestrian yang ramah difabel \\
\hline & & Penanaman Kabel Listrik di Bawah Tanah \\
\hline
\end{tabular}

Sumber: Penulis, 2018

Berikut adalah konsep desain perencanaan dari penataan koridor-koridor jalan di atas dalam bentuk tiga dimensi yang merupakan hasil render image.

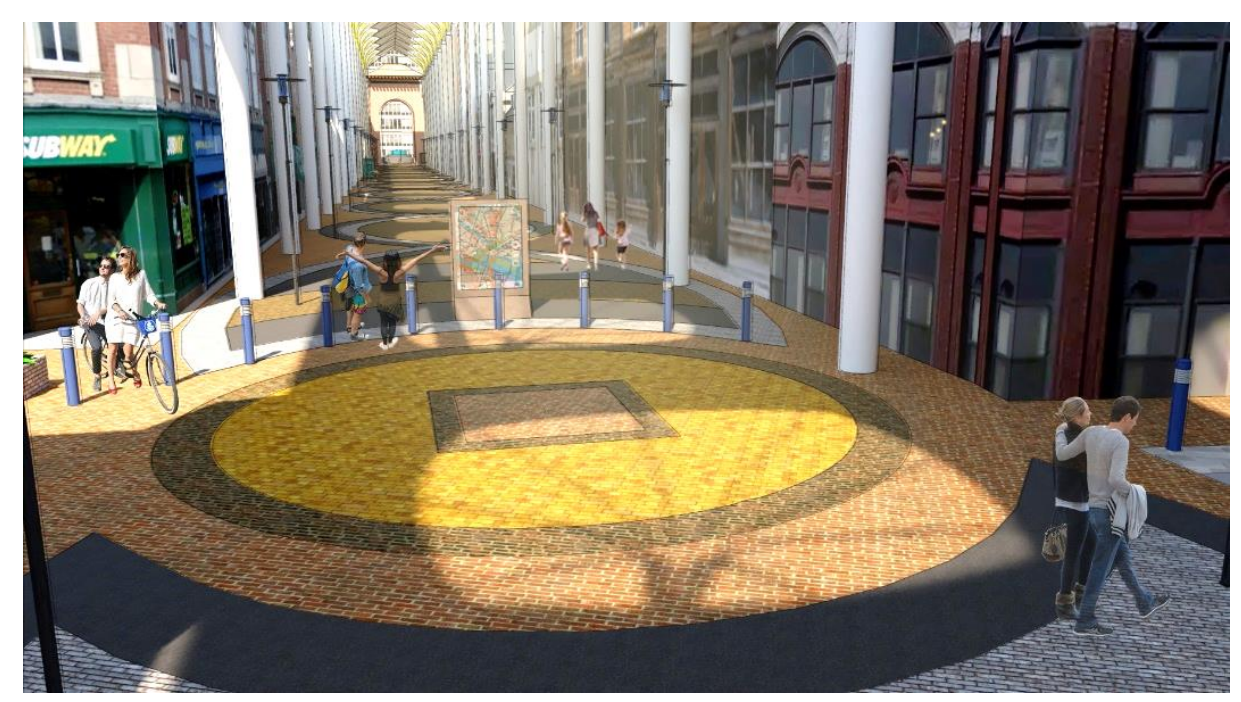

Gambar 4. Konsep Desain Jalan Pasar Baru Sumber: Penulis, 2019 


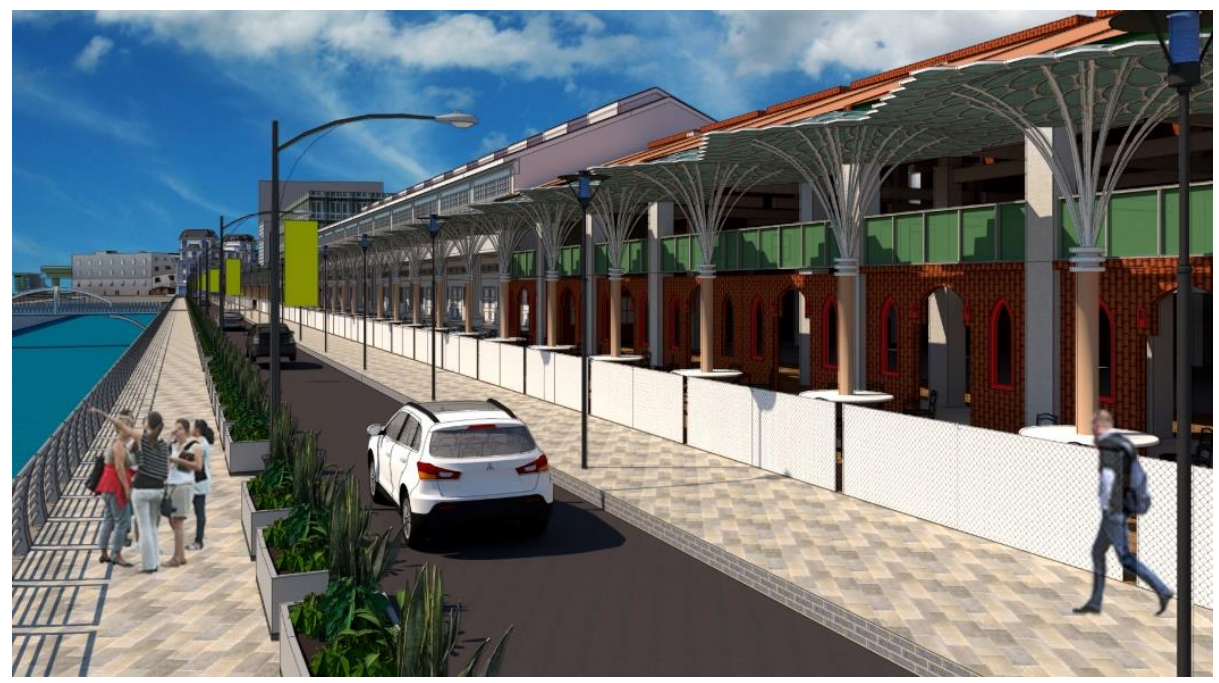

Gambar 5. Konsep Desain Jalan Antara Sumber: Penulis, 2019

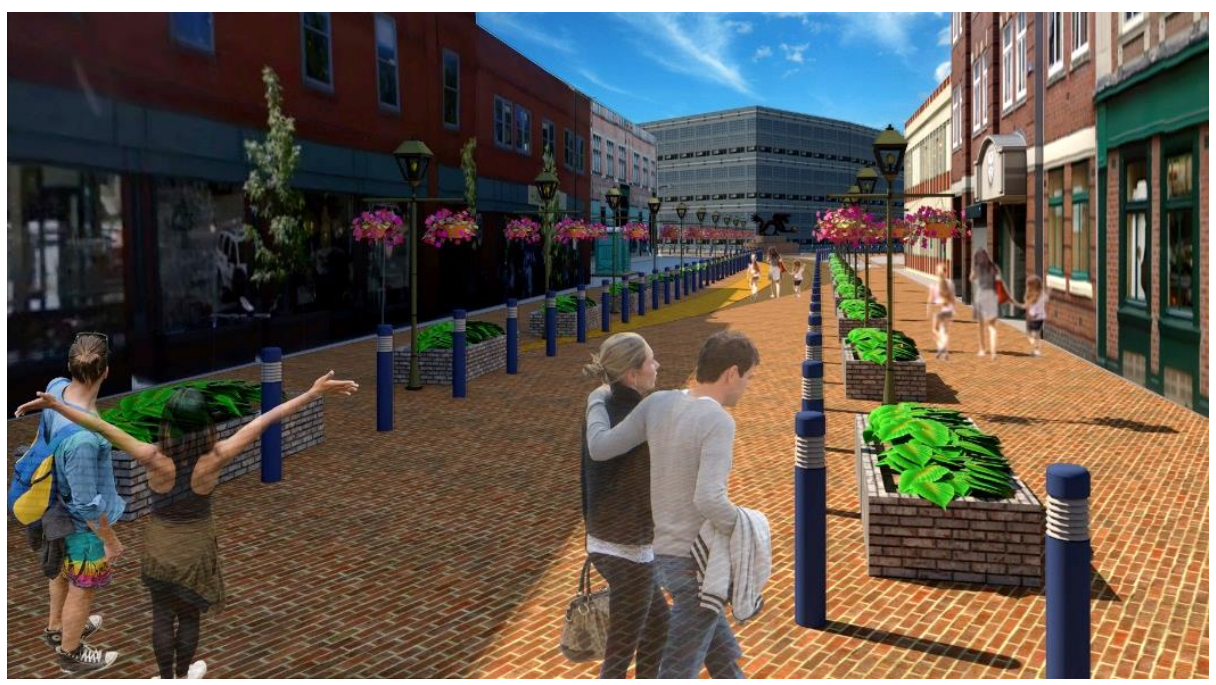

Gambar 6. Konsep Desain Jalan Pintu Air Sumber: Penulis, 2019

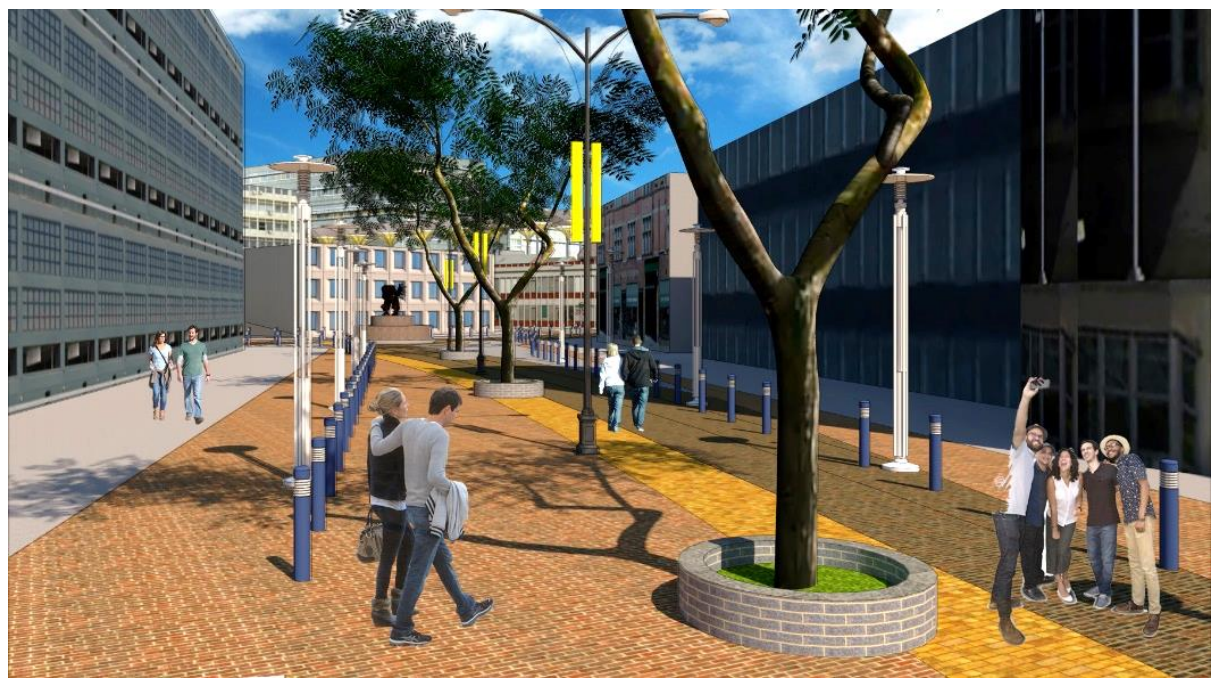

Gambar 7. Konsep Desain Jalan Pintu Air Raya Sumber: Penulis, 2019 


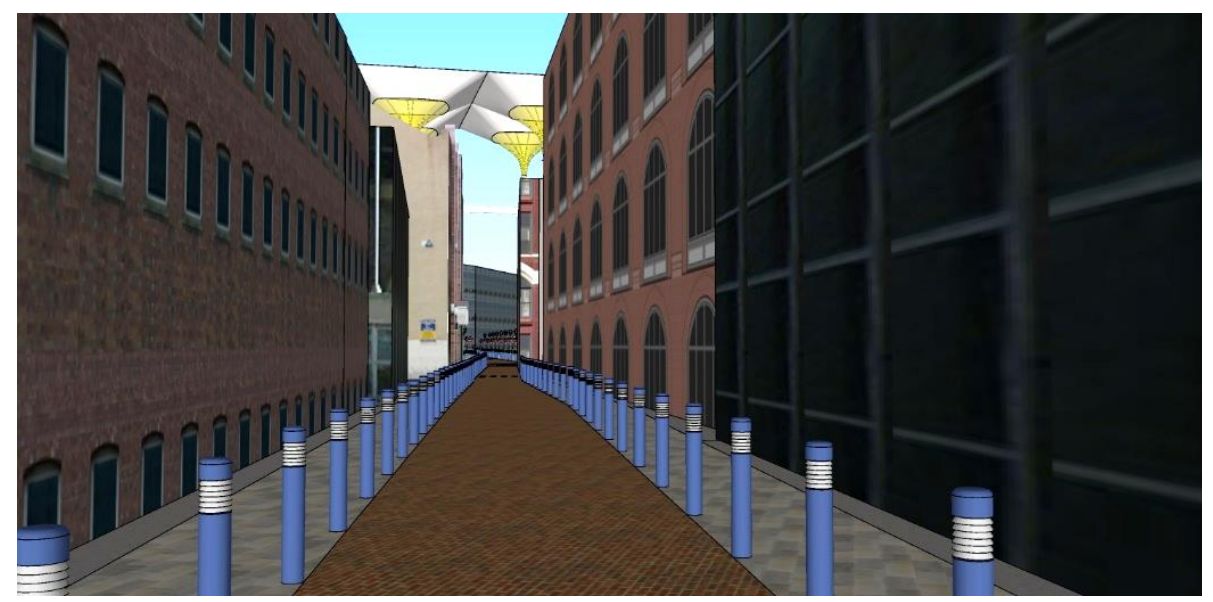

Gambar 8. Konsep Desain Jalan Kelinci Raya Sumber: Penulis, 2019

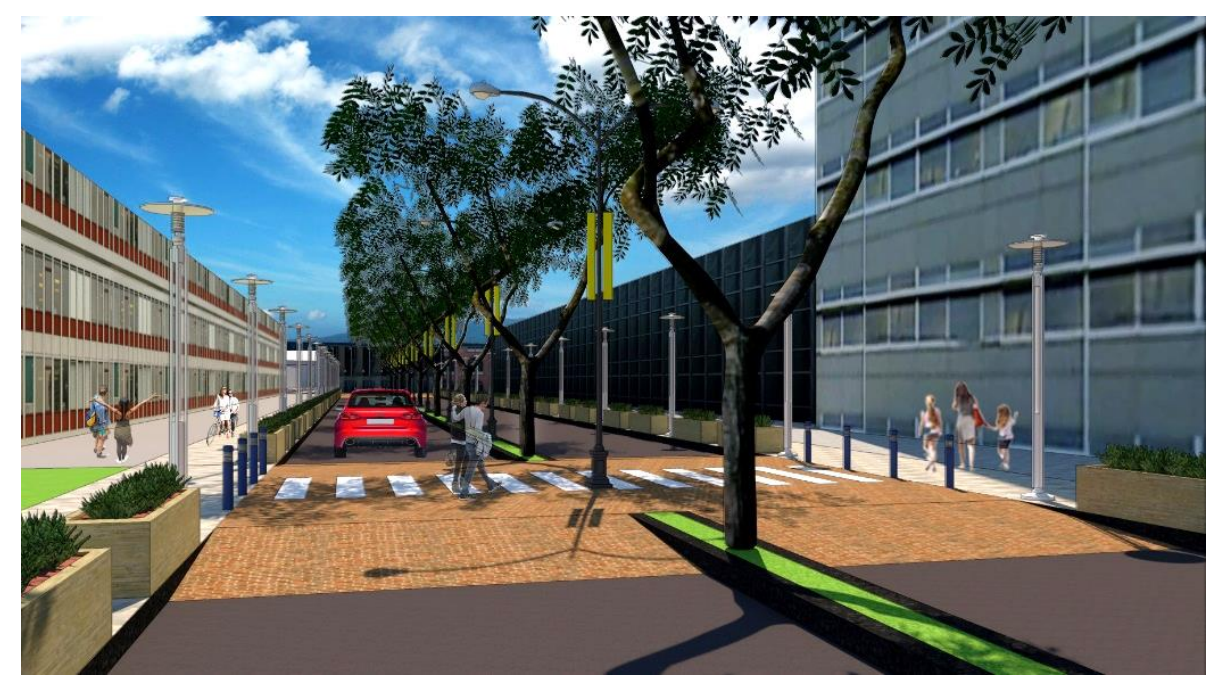

Gambar 9. Konsep Desain Jalan Gereja Ayam Sumber: Penulis, 2019

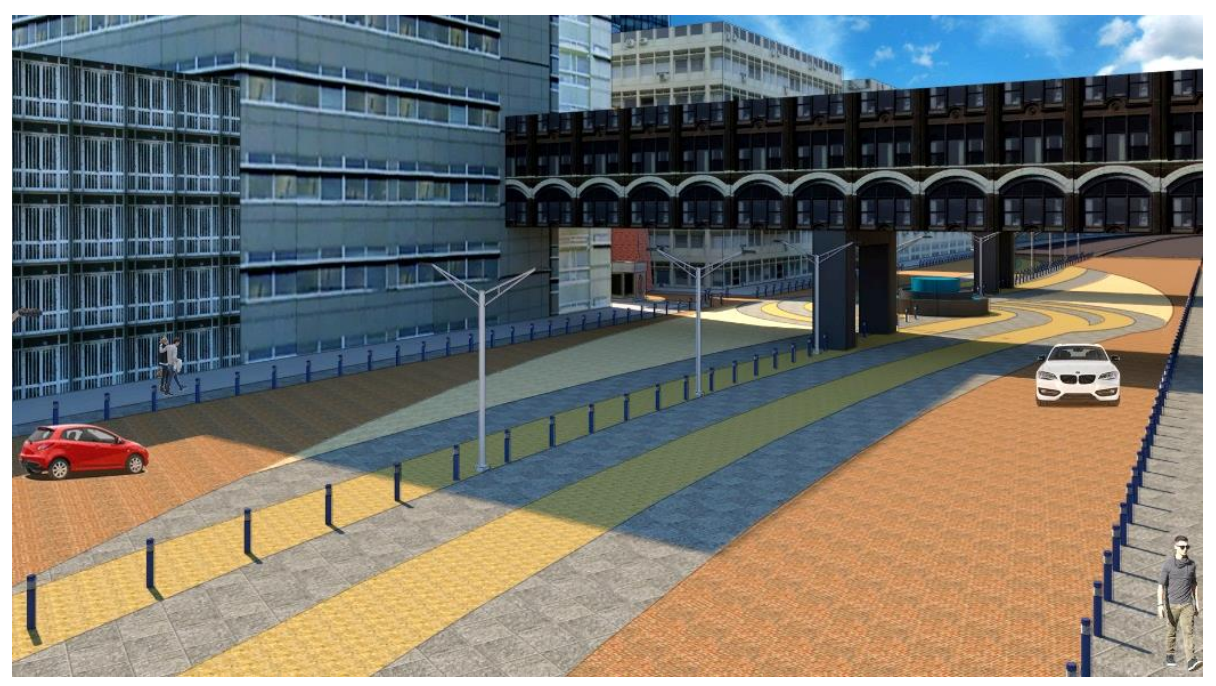

Gambar 10. Konsep Desain Jalan Samanhudi (Pintu Masuk Utara Jl. Pasar Baru) Sumber: Penulis, 2019 


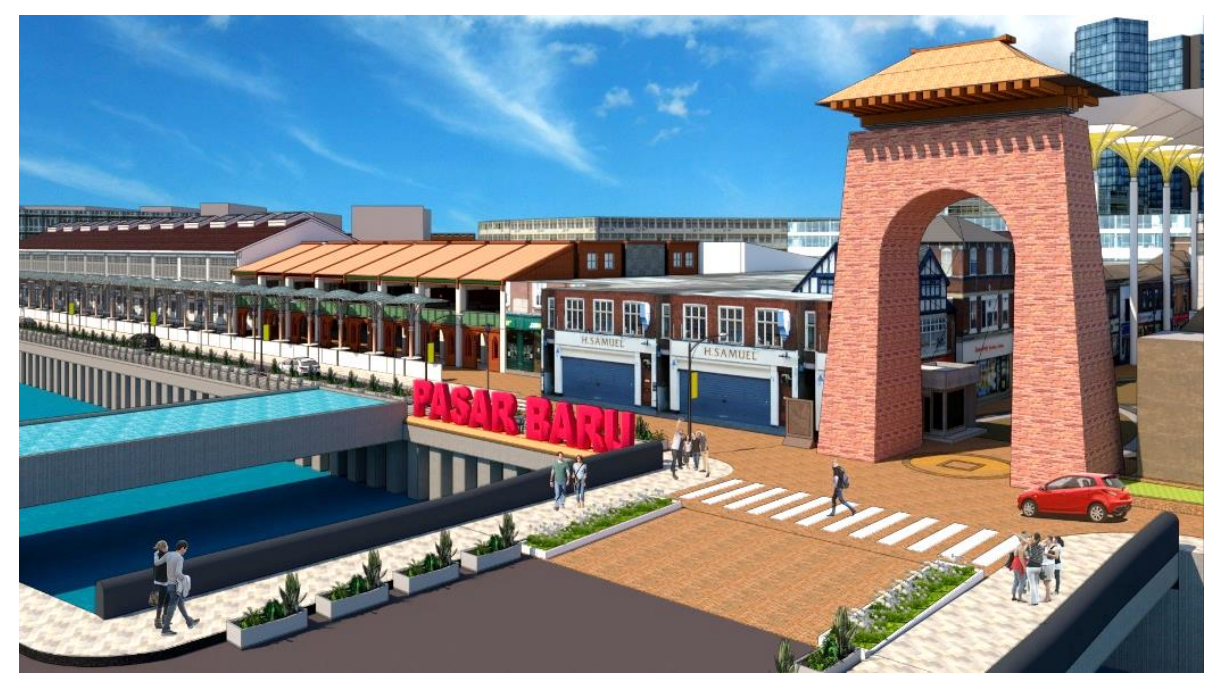

Gambar 11. Konsep Desain Jalan Pasar Baru (Pintu Masuk Selatan) Sumber: Penulis, 2019

\section{KESIMPULAN DAN SARAN}

Revitalisasi Kawasan Perbelanjaan Bersejarah Pasar Baru dibutuhkan untuk meningkatkan daya tarik Pasar Baru agar dapat tetap eksis dan beradaptasi dengan perkembangan zaman serta tren masa kini yang diharapkan dapat meningkatkan nilai sosial ekonomi kawasan tersebut. Keberadaannya Pasar Baru memiliki peranan penting bagi masyarakat, serta memiliki potensi kegiatan ekonomi yang baik, hanya saja banyak fasilitas sarana/infrastrukturnya yang memiliki tingkat peforma yang rendah. Untuk itu, maka Pasar Baru layak untuk ditingkatkan lagi kualitasnya agar tidak kalah saing dengan pusat perbelanjaan modern saat ini. Rencana penataan yang dilakukan yaitu pada infrastruktur jaringan jalan, pedestrian, listrik dan telepon. Penataan mengambil objek bandingan Boat Quay dan Clarke Quay di Singapura, dipadukan dengan filosofi Tiongkok dan arsitektur modern.

Mengingat kawasan Pasar Baru sebagai kawasan bersejarah yang memiliki rekam jejak panjang keberadaannya pada Ibu Kota, seharusnya pemerintah dapat memperhatikan kawasan Pasar Baru sejak lama dan memberikan program khusus dalam upaya pelestarian Pasar Baru. Setidaknya sudah memiliki Urban Design Guide Line kawasan Pasar Baru agar dapat menjadi acuan rencana ke depannya. Dalam pelaksanaan analisis, mengingat keterbatasan waktu yang dimiliki oleh penulis, maka sample responden dari kuesioner terbatas hanya sampai 151 responden. Untuk penelitian kedepannya dapat dilakukan pengambilan responden yang lebih banyak lagi. Karena penelitian ini tidak diketahui jumlah populasinya, sehingga penentuan jumlah responden tidak dapat diketahui, hanya dengan asas semakin banyak responden semakin baik. Para pedagang Pasar Baru menolak apabila Jalan Pasar Baru dijadikan shopping street yang tidak dilalui kendaraan bermotor dengan klaim menjadi sepi pengunjung. Padahal akan sangat menarik apabila Jalan Pasar Baru benar-benar menjadi shopping street seperti Clarke Quay. Pemerintah sebaiknya mencari solusi akan hal tersebut, agar Pasar Baru menjadi shopping street yang sebenarnya dengan tidak dilalui kendaraan bermotor. 


\section{REFERENSI}

Anonim. (2018, September 15). Pengertian Infrastruktur: Arti, Jenis, Komponen, dan Contoh Infrastruktur. Diambil kembali dari Maxmanroe: www.maxmanroe.com/vid/bisnis/pengertian-infrastruktur.html

Badan Pusat Statistik. (2018). Kecamatan Sawah Besar Dalam Angka 2018. Jakarta Pusat, DKI Jakarta, Indonesia: Badan Pusat Statistik Jakarta Pusat.

Danisworo, M. (2018, Maret 25). Pengertian Revitalisasi. Diambil kembali dari Media Urban Planner: www.mediaurbanplanner.wordpress.com/2018/03/25/pengertian-revitalisasi/

Dinas Cipta Karya, Tata Ruang dan Pertanahan Pemerintah Provinsi DKI Jakarta. (2014). Rencana Detail Tata Ruang DKI Jakarta Tahun 2030. Jakarta Pusat, DKI Jakarta, Indonesia.

Direktorat Jenderal Cipta Karya. (1997). Kamus Tata Ruang. Jakarta: Direktorat Jenderal Cipta Karya, Departemen Pekerjaan Umum.

Oliver, D. (2017, September 14). Pasar Baru diusulkan Direnovasi karena Kondisi yang Memprihatinkan. Diambil kembali dari www.megapolitan.kompas.com: www.megapolitan.kompas.com/read/2017/03/15/17474941/pasar.baru.diusulkan.diren ovasi.karena.kondisi.yang.memprihatinkan

Pemerintah DKI Jakarta. (2000). Surat Keputusan Gubernur Provinsi Daerah Khusus Ibu Kota Jakarta Nomor 3048. Jakarta.

Presiden Republik Indonesia. (2009). Undang-Undang Republik Indonesia Nomor 10 Tahun 2009 tentang Pariwisata. Jakarta.

Syarifudin, H. (2017, November 25). Wisata Kota (Urban Tourism). Diambil kembali dari Wordpress: www.habibsyarifudinh.wordpress.com/2017/11/25/wisata-kota-urbantourism/

Yoeti. (1997). Perencanaan dan Pengembangan Pariwisata. Jakarta: PT Pradnya Paramita. 